\title{
Variability of Arctic Sea Ice Thickness Using PIOMAS and the CESM Large Ensemble 0
}

\author{
ZACHARY LABE AND GUDRUN MAGNUSDOTTIR \\ Department of Earth System Science, University of California, Irvine, Irvine, California \\ HAL STERN \\ Department of Statistics, University of California, Irvine, Irvine, California
}

(Manuscript received 27 June 2017, in final form 19 January 2018)

\begin{abstract}
Because of limited high-quality satellite and in situ observations, less attention has been given to the trends in Arctic sea ice thickness and therefore sea ice volume than to the trends in sea ice extent. This study evaluates the spatial and temporal variability in Arctic sea ice thickness using the Pan-Arctic Ice Ocean Modeling and Assimilation System (PIOMAS). Additionally, the Community Earth System Model Large Ensemble Project (LENS) is used to quantify the forced response and internal variability in the model. A dipole spatial pattern of sea ice thickness variability is shown in both PIOMAS and LENS with opposite signs of polarity between the East Siberian Sea and near the Fram Strait. As future sea ice thins, this dipole structure of variability is reduced, and the largest interannual variability is found only along the northern Greenland coastline. Under a high-emissions scenario (RCP8.5) projection, average September sea ice thickness falls below $0.5 \mathrm{~m}$ by the end of the twenty-first century. However, a regional analysis shows internal variability contributes to an uncertainty of 10 to 20 years for the timing of the first September sea ice thickness less than $0.5 \mathrm{~m}$ in the marginal seas.
\end{abstract}

\section{Introduction}

Climate in the Arctic is undergoing rapid change, as the Arctic mean surface temperature is rising at twice the rate of the global mean surface temperature. Accompanying this Arctic amplification is a widespread loss of Arctic sea ice. Quality observations of sea ice concentration (SIC) and, therefore, total sea ice extent (SIE) are available from satellites covering the entire Arctic from 1979. Observations of sea ice thickness (SIT) are very scant by comparison (e.g., Lindsay and Schweiger 2015). In terms of affecting surface turbulent heat fluxes in the Arctic and, therefore, allowing communication between the atmosphere and the underlying ocean, variability in SIC, or the fraction of the grid cell that is covered by sea ice, is more important than SIT. However, it is not clear how sensitive the atmosphere is

Supplemental information related to this paper is available at the Journals Online website: https://doi.org/10.1175/JCLID-17-0436.s1.

Corresponding author: Zachary Labe, zlabe@uci.edu to variability in SIT. Previous studies of the effects of sea ice forcing in an atmospheric global climate model (e.g., Peings and Magnusdottir 2014) have shown that the atmosphere is quite sensitive to the spatial pattern of SIC forcing. Certain spatial patterns of surface forcing in late fall or early winter will excite Rossby waves that may constructively interfere with the climatological stationary waves, leading to perturbations of the stratospheric polar vortex. These perturbations may affect the tropospheric flow some weeks later or in late winter (Peings and Magnusdottir 2014). It is reasonable to assume that the same may apply to SIT forcing, especially when perturbations are enforced in areas of thin ice where the heat flux response is greater. Indeed, Lang et al. (2017) find that thinning Arctic sea ice is a driver of changes in surface heat flux and may locally contribute to surface warming of up to $1^{\circ} \mathrm{C}$ decade $^{-1}$ in winter. The issue of the relative importance of SIT forcing, compared to SIC forcing, remains to be quantified. In this paper, we prepare the groundwork for exploring this issue by examining SIT variability.

Since SIT observations remain scant, we use a sea ice/ ocean, model-produced SIT dataset, the Pan-Arctic Ice 
Ocean Modeling and Assimilation system (PIOMAS; Zhang and Rothrock 2003). Surface meteorological fields (e.g., temperature and wind), as well as sea surface temperature, sea ice velocity, and SIC, are assimilated into PIOMAS, but not the scarce SIT data that are available. PIOMAS output in turn provides temporal and spatial coverage of SIT over the last several decades. Numerous studies (e.g., Schweiger et al. 2011; Laxon et al. 2013; Zygmuntowska et al. 2014; Stroeve et al. 2014; Wang et al. 2016) have evaluated and compared the satellite and model-based products for their representation of SIT. While PIOMAS is model produced or a reanalysis product, it provides a spatially and temporally complete simulation of Arctic SIT over the satellite era (from 1979).

Global climate model simulations of SIT, such as from phase 5 of the Coupled Model Intercomparison Project (CMIP5), indicate significant model uncertainty in the spatial distribution and variability of SIT (BlanchardWrigglesworth and Bitz 2014; Stroeve et al. 2014; Melia et al. 2015). In addition to model biases and intermodel spread, internal variability contributes to large uncertainties in future Arctic climate conditions including SIT (e.g., Kay et al. 2011; Swart et al. 2015; Jahn et al. 2016; Swart 2017; W. Yang and G. Magnusdottir 2018, manuscript submitted to Sci. Rep.). We can address internal variability by using output from the recent Community Earth System Model Large Ensemble Project (CESM-LENS; Kay et al. 2015). We use 40 ensemble members of climate simulations for the twentieth and twenty-first centuries. The CESM is a later version of the model than the one that contributed to CMIP5, and its atmospheric component (CAM5) has superior representations of physical processes in the Arctic and was the version used by Peings and Magnusdottir (2014). By averaging over all ensemble members, we estimate the forced signal in the climate system as internal variability, which has the characteristics of white noise. Here, we assess pan-Arctic spatial and temporal variability of SIT in the LENS over the historical period (1920-2005) and in future projections (2006-80) under a high-emissions scenario (RCP8.5).

This paper is organized as follows. Section 2 describes SIT observations from submarine and satellite platforms, SIT from PIOMAS, and SIT data from LENS. Section 3 describes the methods of analysis. Results are presented in section 4 . In section 4a, we assess the spatial and temporal variability of SIT from PIOMAS and compare with observational SIT products. In section $4 \mathrm{~b}$, we evaluate trends and variability from the start of the historical LENS simulations (1920) through the PIOMAS record (until 2015). We also compare regional SIT measures/estimates between PIOMAS and LENS. In section $4 c$, we investigate future projections of SIT, including the spatial patterns of sea ice thinning. Section 5 contains a summary of our study and some concluding remarks.

\section{Data}

Observations of SIT remain very sparse, compared to observations of SIC, which have a continuous satellite record from 1979 to the present. SIT is not measured directly by satellite; rather, it is freeboard that is measured, or the height of the sea ice above the ocean surface, from which SIT may be calculated, given the depth of snow on top of the sea ice and hydrostatic equilibrium. One satellite mission (ICESat) evaluating SIT does not provide continuous measurements; rather, they only offer readings over two periods of the annual cycle, close to the minimum SIT in fall and close to the maximum SIT in spring. While the other satellite mission (CryoSat-2) provides weekly and monthly data, its SIT estimates are only available during the cold season due to melt pond formation in the summertime. Only observations from submarines offer direct measurements of SIT, but those measurements are limited by small areal extent and sporadic temporal coverage. We are left with model-generated fields for assessment of SIT for climate studies. Model-assimilated products or reanalysis of SIT offers the aerial and temporal coverage that is required for a climate study over the observational period of SIC. For insight about possible SIT later in this century, we call on the CESM Large Ensemble. By averaging over all 40 ensemble members, we get a good approximation of the forced signal toward the end of the century, albeit from one climate model. Below, we further discuss each of these sources of SIT data.

\section{a. Submarine}

Submarine SIT data were retrieved from upwardlooking sonar (ULS) instruments during missions in the 1980s and 1990s (Lindsay 2010). We utilize gridded ULS data from 1986 to 1994 (http://nsidc.org/data/ NSIDC-0690/versions/1). SIT in this dataset were interpolated onto a 100-km EASE grid (Brodzik et al. 2012) by averaging thicknesses within $70 \mathrm{~km}$ of a grid cell. A more comprehensive archive of ULS and mooring data (Unified Sea Ice Thickness Climate Data Record) is provided by the University of Washington Polar Science Center (Lindsay 2010).

\section{b. ICESat and CryoSat-2}

The poor spatial and temporal coverage of satellite data of Arctic SIT remains a significant challenge. Retrieved from its Geoscience Laser Altimetry System 
(GLAS), NASA's ICESat provided one of the first estimates of near pan-Arctic SIT measurements during 10 campaigns from 2003 through 2009. SIT is calculated from freeboard measurements following the methods of Kwok and Cunningham (2008) and Kwok and Rothrock (2009). Additionally, another dataset of ICESat SIT is available from the NSIDC (http://nsidc.org/data/docs/daac/ nsidc0393_arctic_seaice_freeboard/index.html) following the slightly different calculation of freeboard to SIT by Zwally et al. (2002). We focus on the JPL gridded dataset (https://rkwok.jpl.nasa.gov/icesat/index.html) and therefore denote it as "ICESat-J." We have elected to use the JPL product of gridded SIT, as its uncertainties have been widely assessed in prior comparisons (e.g., Kwok and Cunningham 2008; Zygmuntowska et al. 2014). The ICESat campaigns $(\approx 34$ days each) were selected to correspond with the climatological maximum (spring) and minimum (autumn) SIT. Thickness is derived from laser altimeter satellite measurements of freeboard (height of the ice above the ocean surface) and assuming hydrostatic equilibrium. Snow depth is estimated following the methods of Kwok and Cunningham (2008) by constructing daily snow fields from ECMWF snow accumulation. Zygmuntowska et al. (2014) provide a comprehensive overview of the uncertainties in these derived SIT estimates from ICESat.

The ESA launched the CryoSat-2 satellite in 2010, which similarly uses a radar altimetry system to measure freeboard and then derives SIT (Laxon et al. 2013), given the assumptions above. Again, biases and uncertainties may arise from snow and ice density calculations, along with estimating the snow-ice interface. Laxon et al. (2013) finds a difference of $0.1 \mathrm{~m}$ in SIT when averaged over the Arctic domain, compared to in situ observations. CryoSat-2 provides weekly and monthly data, but not in the summertime, as a result of inaccuracies from radar backscattering over melt ponds. CryoSat-2 snow depth on multiyear ice is estimated from Warren et al. (1999). However, snow depth on first-year ice is calculated from $50 \%$ of the Warren et al. (1999) snow depth estimates (Laxon et al. 2013). Considering the various methods and datasets, snow depth remains one of the greatest uncertainties in deriving SIT from freeboard altimetry measurements. In many cases, only climatological values of snow depth and densities of sea ice and snow are used in these estimations. Because of variable weather conditions in the Arctic, these climatologies may not be representative of the actual snow depth on top of ice.

\section{c. PIOMAS}

PIOMAS is a coupled ice-ocean model assimilation system (Zhang and Rothrock 2003) forced by NCEPNCAR reanalysis. Monthly SIT, SIC, and snow depth output fields are available from 1979. PIOMAS couples the Parallel Ocean Program ocean model (Smith et al. 1992) with a 12-category thickness and enthalpy sea ice model (Zhang and Rothrock 2003). The atmospheric forcing includes 2-m surface air temperature, 10-m surface winds, cloud fraction, and downwelling longwave radiation. Downwelling shortwave radiation is calculated following the methods of Parkinson and Washington (1979) using 2-m surface air temperature and cloud fraction. It should be noted that ice-ocean models (like PIOMAS) do not have an atmospheric model component and therefore are subject to inaccuracies from the forcing reanalysis data (Hunke and Holland 2007; Lindsay et al. 2014). Using PIOMAS forced by four different global reanalysis datasets, Lindsay et al. (2014) found a range in estimates of simulated sea ice volume (SIV) trends, especially before any model bias correction is applied to each dataset. Despite differences in the total trends of SIV, these simulations produced similar spatial patterns of SIT. PIOMAS has the capability of assimilating SIC, sea ice velocity (Lindsay and Zhang 2006), and sea surface temperature following the methods of Manda et al. (2005). However, PIOMAS does not currently assimilate any satellite SIT data. Snow depth is estimated from NCEP-NCAR precipitation, and Lindsay and Schweiger (2015) estimate the uncertainty to be approximately $0.1 \mathrm{~m}$. The model is available on a generalized orthogonal curvilinear coordinate system with a mean resolution of $22 \mathrm{~km}$ with the highest resolution over the Greenland Sea, Baffin Bay, and eastern Canadian Arctic Archipelago.

PIOMAS has been extensively validated with satellite, submarine, airborne, and in situ observations (e.g., Zhang and Rothrock 2003; Schweiger et al. 2011; Laxon et al. 2013; Stroeve et al. 2014; Wang et al. 2016) and compared well with these observations. Schweiger et al. (2011) found a less than 0.1-m mean difference and high pattern correlation $(\mathrm{r}>0.8)$ between PIOMAS and ICESat SIT fields. Stroeve et al. (2014) and Wang et al. (2016) found that PIOMAS overestimates thin ice and underestimates thick ice when compared with a variety of different observational datasets. BlanchardWrigglesworth and Bitz (2014) also show that PIOMAS and other ice-ocean models have reduced variability due to their thermodynamic and dynamic mechanisms on simulated SIT. While PIOMAS sea ice fields are model generated and sensitive to atmospheric reanalysis forcings, the spatial patterns, seasonal cycle, and trends in SIT and SIV are realistically reproduced. A closer analysis of PIOMAS uncertainty can be found by Schweiger et al. (2011). They find a SIV trend of $-2.8 \times 10^{3} \mathrm{~km}^{3} \mathrm{decade}^{-1}(1979-2010)$ and estimate 

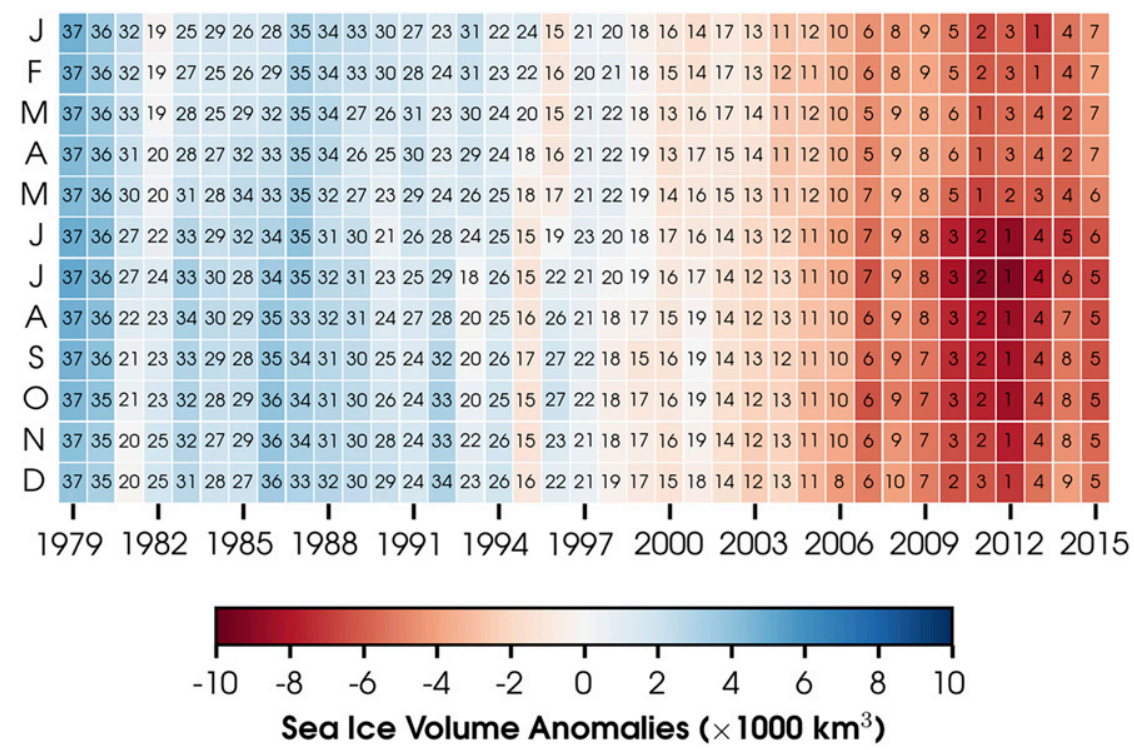

FIG. 1. PIOMAS Arctic SIV anomalies (color gradient) for each month over the period from 1979 to 2015 . The 37 years are ranked (black numbers) for each month by total volume; therefore, "1" identifies the lowest SIV in the 37-yr record for each individual month.

the uncertainty at $1 \times 10^{3} \mathrm{~km}^{3} \mathrm{decade}^{-1}$. Comparing PIOMAS with available March and October ICESat and CryoSat-2 data also demonstrates that PIOMAS may underestimate the trend in SIV loss (Schweiger et al. 2011).

While ICESat and CryoSat-2 provide recent satellite observations of SIT, their limited temporal availability $(\approx 5$ years each $)$ and limited areal coverage of SIT restrict the ability to quantify the interannual variability and long-term trends in the SIT and SIV records. Additionally, it has been shown (e.g., Zygmuntowska et al. 2014) that large uncertainties and biases may exist among satellite methods for ice age, ice density, and snow depth when deriving SIT. PIOMAS closely compares with observational (submarine and satellite) SIT spatial patterns and average SIT.

\section{d. CESM Large Ensemble Project}

To assess internal variability of Arctic SIT, we use the CESM-LENS, consisting of 40 ensemble members covering 1920 to 2100 . Each ensemble member is run with the fully coupled CESM1.1 model, forced using historical data from 1920 to 2005, and then followed by a RCP8.5 scenario from there on to 2100 . The large number of ensemble members is useful in characterizing the internal variability in the climate system and thereby isolating the forced signal.

Previous studies (e.g., Stroeve et al. 2014) evaluated SIT from CMIP5, which contains a large number of models; each one has different climate sensitivity and amplitude of feedback mechanisms, leading to a very different Arctic amplification (e.g., Andrews et al. 2012). The studies suggest that uncertainties due to model biases, as well as internal variability, need to be considered in order to realistically represent Arctic SIT. Here, we use a single climate model (the CESM), but one that has been widely used in climate studies. By averaging over multiple ensemble members, we can largely eliminate internal variability. Recent studies have assessed SIE trends and SIC variability in LENS and show strong internal variability among ensemble members (e.g., Barnhart et al. 2016; Swart et al. 2015; W. Yang and G. Magnusdottir 2018, manuscript submitted to Sci. Rep.). In this study, we evaluate the patterns of SIT variability during the satellite period and twentieth century using PIOMAS and LENS, respectively. We also consider future projections of SIT in LENS. It is the first study to comprehensively evaluate SIT variability in LENS.

\section{Methods}

We compare submarine, satellite products (ICESat-J and CryoSat-2), and PIOMAS on 100-km EASE grids, masked by their respective spatial coverage domains. CryoSat-2 covers the entire Arctic basin. In contrast, the ICESat-J SIT data are not available over the Atlantic sector of the Arctic Ocean, including portions of the Barents and Kara Seas. The ULS submarine data are limited in coverage to the region just north of Greenland. 


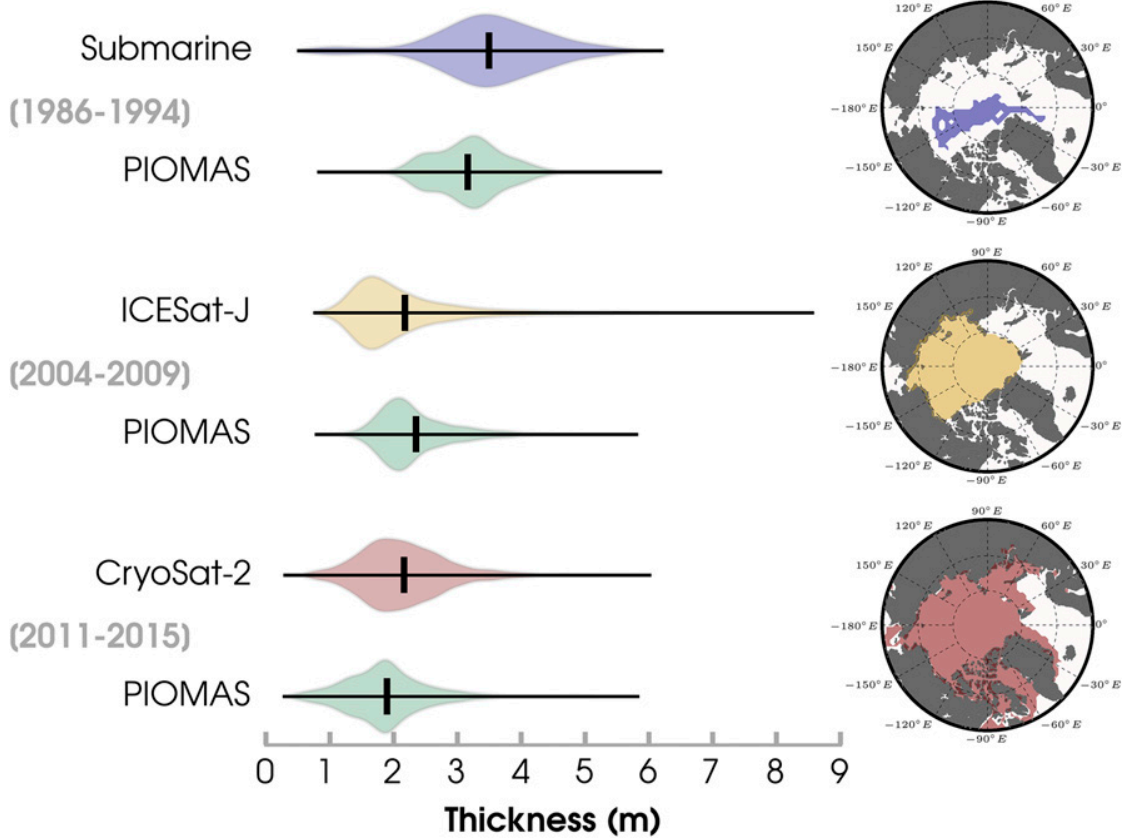

FIG. 2. Violin plots showing distributions (left column) of March SIT from PIOMAS and three observational datasets, each plotted over the years of operation of the observation platform. (top) PIOMAS and submarine (1986-94); (middle) PIOMAS and ICESat-J (2004-09); (bottom) PIOMAS and CryoSat-2 (2011-15). The domain that the three different observation platforms cover is shown on the right. Data are interpolated onto a common 100-km EASE-Grid. The mean is indicated by a bold black line in each violin plot.

We compare SIT between the observational products and PIOMAS without considering SIC (therefore, SIT is averaged over the entire grid cell). However, for comparing the two model-produced SIT datasets (PIOMAS and LENS), we use the effective SIT ( $h_{\text {eff }}=$ SIT $\cdot$ SIC). The difference between these two methods of assessing SIT is largest during fall and is mostly confined to the outer marginal seas (generally $<1 \mathrm{~m}$ ).

Average SIT is estimated by area weighting SIT for grid cells with a thickness of at least $0.15 \mathrm{~m}$ north of $65^{\circ} \mathrm{N}$. The $0.15-\mathrm{m}$ mask excludes grid cells with largely open seawater. Thus, total SIV in LENS and PIOMAS is computed by

$$
\mathrm{SIV}=\sum_{i} h_{\mathrm{eff}_{\mathrm{i}}} a_{i}
$$

where $h_{\text {eff }}$ is the effective thickness, and $a_{i}$ is the area of the grid cell. All sea ice calculation estimates are on monthly time scales.

Data comparing PIOMAS and LENS are regridded onto a common $1^{\circ}$ latitude $\times 1^{\circ}$ longitude spacing using a piecewise linear interpolation method. We apply EOF analysis to monthly linearly detrended SIT fields in LENS and PIOMAS using the Dawson (2016) Python package. EOF analysis in LENS is performed by appending all of the ensemble members together. Before computing EOFs, the SIT fields are weighted by the square root of the cosine of their latitude to account for converging meridians toward the pole. To examine regional SIT variability, we further divide the Arctic Ocean into six subdomains chosen by similar mean spatial SIT (north of $65^{\circ} \mathrm{N}$ ). These areas are shown in Fig. S1 and represent the following: central Arctic basin (north of $85^{\circ} \mathrm{N}$ ), northern Canadian Arctic Archipelago and Greenland coast, Beaufort and Chukchi Seas, East Siberian Sea, Laptev Sea, and Barents and Kara Seas. Areas in the outer marginal seas, such as Bering Sea, Baffin Bay, Sea of Okhotsk, and the southern Canadian Arctic Archipelago, are excluded, as sea ice cover is generally only present in winter.

\section{Results}

a. PIOMAS and observational sea ice thickness data

In a similar method to the SIE visualizations in Parkinson and DiGirolamo (2016), Fig. 1 uses a color gradient to show PIOMAS SIV anomalies over the 1979 to 2015 period, using $1981-2010$ as climatology. The overall volume rankings from highest (rank of 37) to lowest (rank of 1) are also displayed for each month in 

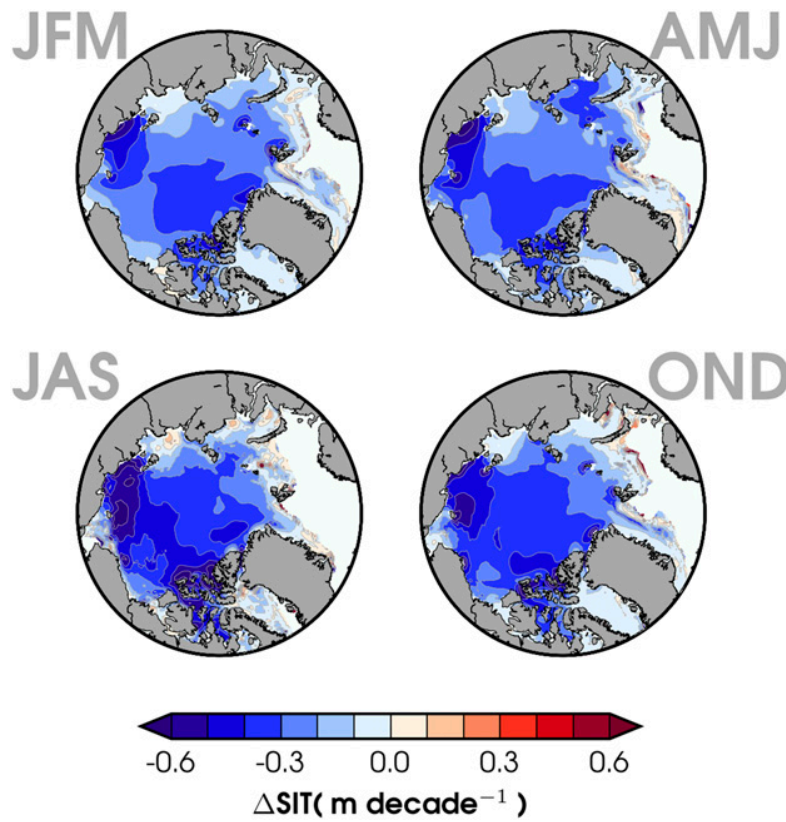

FIG. 3. Linear trends in PIOMAS SIT from 1979 to 2015 in $\mathrm{m}$ decade ${ }^{-1}$ calculated over each season. Contour intervals are $0.1 \mathrm{~m} \mathrm{decade}^{-1}$.

the time series. For instance, a ranking of " 1 " is the lowest total SIV for that respective month over the time series. While there is considerable interannual variability, there is a net loss of SIV in every month of the year during the satellite era. More recently, since 2007, SIV anomalies are greatest in summer (JJA). This is in contrast to the recent greatest total SIE anomalies (and largest variability) in September, which is the climatological end of the melt season (Serreze and Stroeve 2015; Serreze et al. 2016). A study by Bushuk et al. (2017) found that this enhancement of the summertime anomaly is driven by a positive feedback between SIT and ice-albedo and is affected by melt pond formation, snowfall, and SIC.

To compare the depiction of SIT distributions in the various datasets, we show violin plots of their March SIT in Fig. 2. Violin plots are useful in visualizing a kernel density estimate to show the shape of the distribution on each side of the center axes. Each observational product is compared with PIOMAS over the relevant period (shown in brackets on the left-hand side) and spatial domain (shown in the right-hand column). The means of the distributions are shown by black bold ticks. The difference in mean SIT between the various observational products and PIOMAS is, in all cases, less than $0.4 \mathrm{~m}$. A larger range in ICESat-J's March SIT values is found. However, this difference may in part be due to an overestimation of SIT near Greenland from ICESat-J due to the choice of sea ice density (Zygmuntowska et al. 2014). Greater variability is found in both submarine
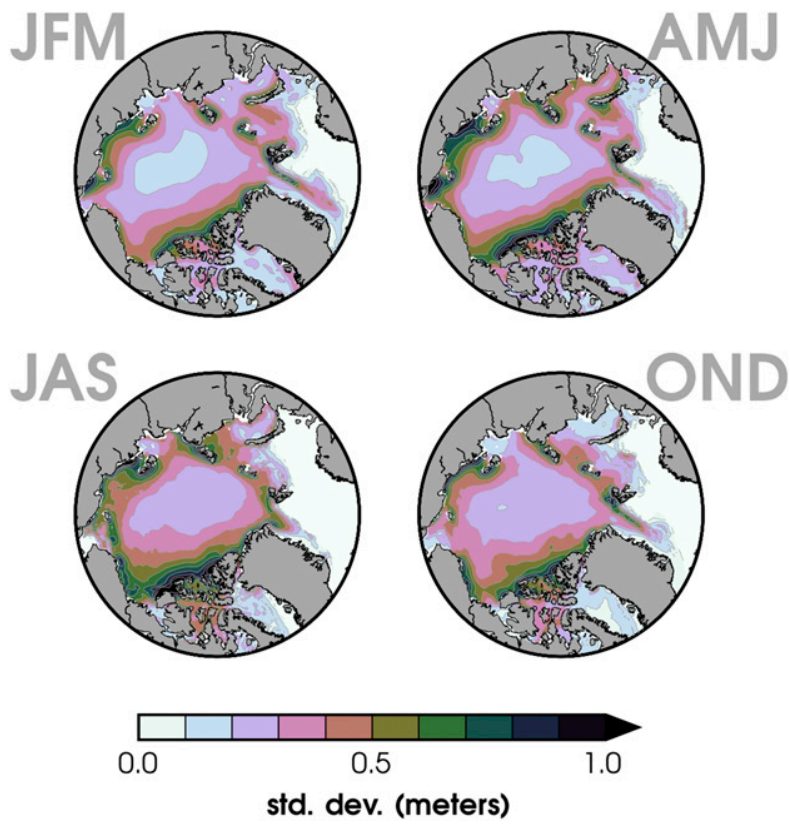

FIG. 4. Standard deviations (m) of PIOMAS SIT averaged for each season. The monthly SIT at each grid point is first linearly detrended before calculating the standard deviation. Contour intervals are $0.1 \mathrm{~m}$.

and ICESat-J estimates with standard deviations of 0.96 and $0.91 \mathrm{~m}$ when compared with PIOMAS of 0.61 and $0.64 \mathrm{~m}$, respectively. Standard deviations are similar in CryoSat-2 and PIOMAS and correspond to 0.71 and $0.70 \mathrm{~m}$. Overall, the closest agreement is found between CryoSat-2 and PIOMAS.

Comparing spatial differences between gridded SITs in the various observations suggests PIOMAS consistently underestimates in regions of thicker ice and overestimates in regions of thinner ice. This is particularly noticeable in the comparison of gridded submarine and ICESat-J with PIOMAS SIT over the region of climatologically thickest ice north of Greenland and along the coastline in the Greenland Sea (not shown). These results are consistent with earlier studies (e.g., Schweiger et al. 2011; Laxon et al. 2013; Stroeve et al. 2014; Wang et al. 2016).

PIOMAS produces a similar SIT spatial distribution, compared with submarine and satellite data. While there are small regional differences as previously noted, all SIT comparisons show reasonable agreement over space and time and support the use of a PIOMAS climatological record. Henceforth, we will use PIOMAS SIT for our analysis. Additional information about PIOMAS SIT uncertainties and biases are detailed in Schweiger et al. (2011).

We calculated linear (least squares) SIT trends over overlapping 10-yr periods from 1980 to 2015 (not 


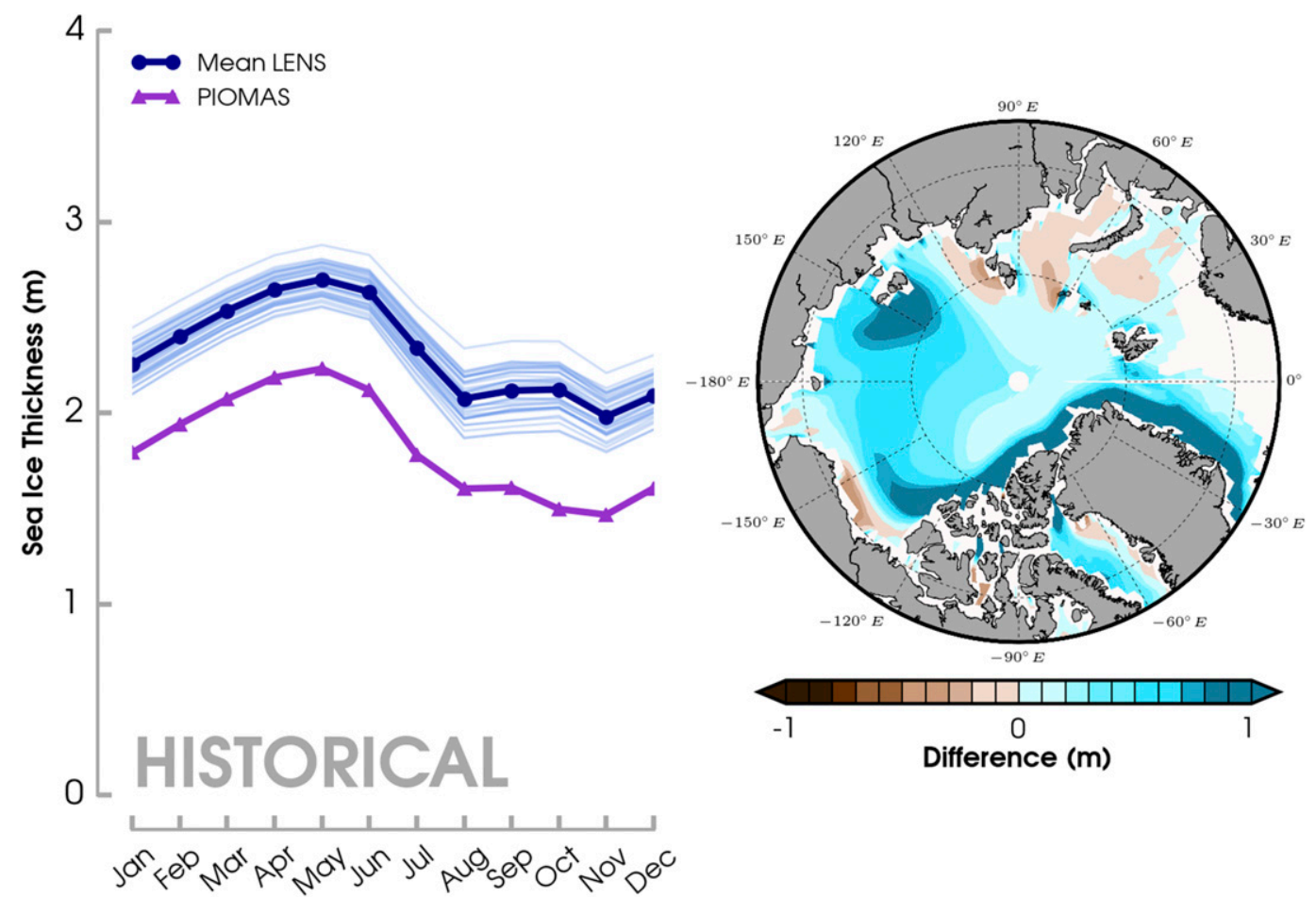

FIG. 5. (left) Seasonal cycle of SIT (north of $65^{\circ} \mathrm{N}$ ) calculated for PIOMAS and LENS. All 40 ensemble members are used for LENS, but only over the period overlapping with PIOMAS (1979-2015). Each LENS member is denoted by a light blue line and the ensemble mean in dark blue. (right) The difference in mean annual SIT between the ensemble mean of LENS and PIOMAS. Contour intervals are $0.1 \mathrm{~m}$.

shown). Shorter periods over the PIOMAS time series reveal large variability in SIT trends, particularly across the Beaufort, Chukchi, and East Siberian Seas. However, over the entire time series (1979-2015), decadal trends shown by season in Fig. 3 indicate an extensive thinning of sea ice across the Arctic Ocean basin in all seasons and especially north of the Canadian Arctic Archipelago and in the East Siberian Sea.

We evaluate interannual variability of SIT in PIOMAS, as in Blanchard-Wrigglesworth and Bitz (2014), by calculating standard deviation of linearly detrended monthly thickness, here for each season, shown in Fig. 4. The greatest variability is found along the coastlines, especially north of the Canadian Arctic Archipelago and in the East Siberian Sea, during all seasons. Areas of thicker ice (such as north of Greenland) often have higher variability. The lowest variability in all seasons is found in the central Arctic basin.

\section{b. Regional sea ice thickness variability (1920-2015)}

We use the CESM-LENS to evaluate regional SIT variability over historical (1920-2005) and future (RCP8.5; 2006-80) periods (section 4c). Previous studies have shown that LENS realistically reproduces the interannual cycle and internal variability of Arctic SIC
(Barnhart et al. 2016; Swart et al. 2015; Jahn et al. 2016; W. Yang and G. Magnusdottir 2018, manuscript submitted to Sci. Rep.). Our analysis is focused on SIT variability in LENS, which has not been previously addressed. In this subsection, we combine a few years of projected LENS (specifically 2006-15) with the part of the historical period that overlaps with PIOMAS (19792015). Figure 5 compares the SIT seasonal cycle from PIOMAS with LENS over the 1979-2015 time period. The ensemble mean of LENS overestimates SIT by $0.5 \mathrm{~m}$, on average, in the annual mean. All of the LENS members closely reproduce the PIOMAS SIT seasonal cycle, with only minor differences in the timing of the minimum thickness in late fall. Ensemble spread is greatest in September at approximately $0.48 \mathrm{~m}$ between the maximum and minimum ensemble members and decreases to $0.32 \mathrm{~m}$ in May (near the SIT climatological maximum). The difference in the spatial distribution of the annual mean SIT between the ensemble mean of LENS and PIOMAS (1979-2015) is shown on the righthand side of Fig. 5. The LENS mean is thicker by more than $1 \mathrm{~m}$ along coastal Greenland, the northern Canadian Arctic Archipelago, and near the New Siberian Islands in the East Siberian Sea. These areas are located near the greatest variability expressed by PIOMAS SIT, as seen in 


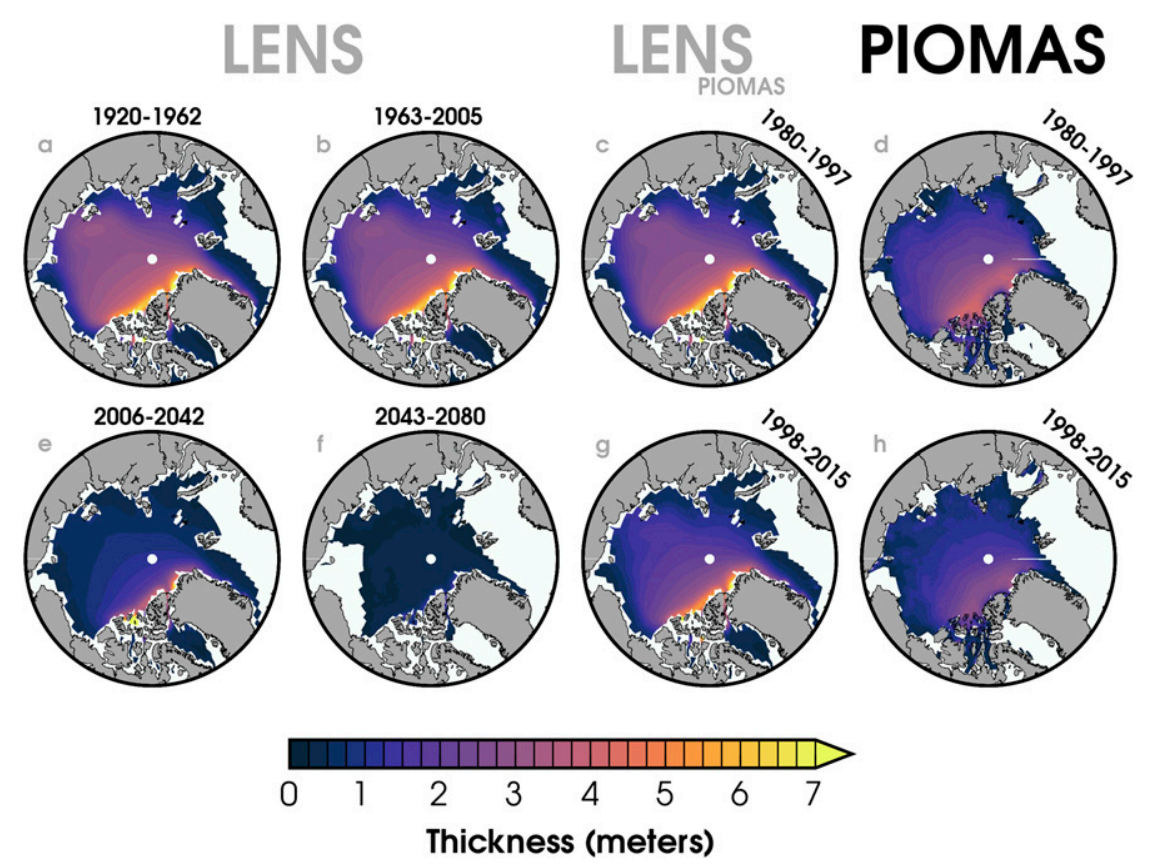

FIG. 6. September SIT composites from the historical and future LENS ensemble average and from PIOMAS (right column). The LENS ensemble mean (1920-2080) is composited over four different equal-length time periods shown in the two left-hand columns (1920-62, 19632005, 2006-42, and 2043-80). Furthermore, for comparison with PIOMAS, the third column shows the LENS ensemble mean over (top) 1980-97 and (bottom) 1998-2015.

Fig. 4, and in areas where PIOMAS consistently underestimates thick ice along coastal Greenland.

In Fig. S2, we assess our six defined sea ice regions (Fig. S1) for comparisons between LENS and PIOMAS. Comparing the differences between the historical LENS mean and PIOMAS in September from 1979 to 2015, we find close agreement for average SIT in the central Arctic basin, the Barents-Kara Seas, and the Laptev Sea (Fig. S2). The largest differences are north of Greenland $(>1 \mathrm{~m})$, the Beaufort and Chukchi Seas, and in the East Siberian Sea, where the ensemble mean has thicker sea ice than PIOMAS. March differences between the LENS mean and PIOMAS (not shown) are approximately the same magnitude as in September for all regions.

To get a quick overview of the spatial character of September SIT in LENS and PIOMAS, Fig. 6 represents a composite, first from LENS over the historical period split into two equal time periods shown in Figs. 6a and 6b, for 1920-62 and 1963-2005. We also composited September SIT in LENS so that it overlapped with the PIOMAS time period, 1980-2015. These are shown in Fig. 6c (1980-97) and Fig. 6g (1998-2015) and should be compared with the equivalent field from PIOMAS shown in Figs. 6d and 6h. The LENS composite of projected SIT (shown in Figs. 6e,f) will be discussed in section 4c. There is little change in the spatial distribution of SIT in the historical LENS until the late 1990s. From then on, there is a thinning of sea ice across much of the central Arctic basin. A comparison of the LENS PIOMAS composites and PIOMAS shows that the ensemble mean has thicker ice extending from the central Arctic basin into the East Siberian and Laptev Seas (Fig. 6, two right-hand columns). Further, LENS $_{\text {PIOMAS }}$ has an area of thicker sea ice extending along the east coast of Greenland from the Fram Strait. These regions of thicker sea ice in LENS PIOMAS are present in both periods (1980-97 and 1998-2015). In contrast, PIOMAS only distributes its region of thicker ice $(>3 \mathrm{~m})$ close to Greenland and the northern Canadian Arctic Archipelago coast. The latter half of the PIOMAS time series is consistent with a general thinning over all sea ice covered areas.

To investigate regions of SIT variability in PIOMAS and the historical LENS, we use EOF analysis to determine the primary modes of variability. The first leading mode in the historical (1920-2005) LENS (EOF1; representing $41 \%$ of the variance) is depicted in Fig. 7 and has opposite-sign centers of action near the New Siberian Islands and close to Svalbard. This pattern corresponds to the northern annual mode (NAM) in the atmosphere, which is the first mode of variability of the 

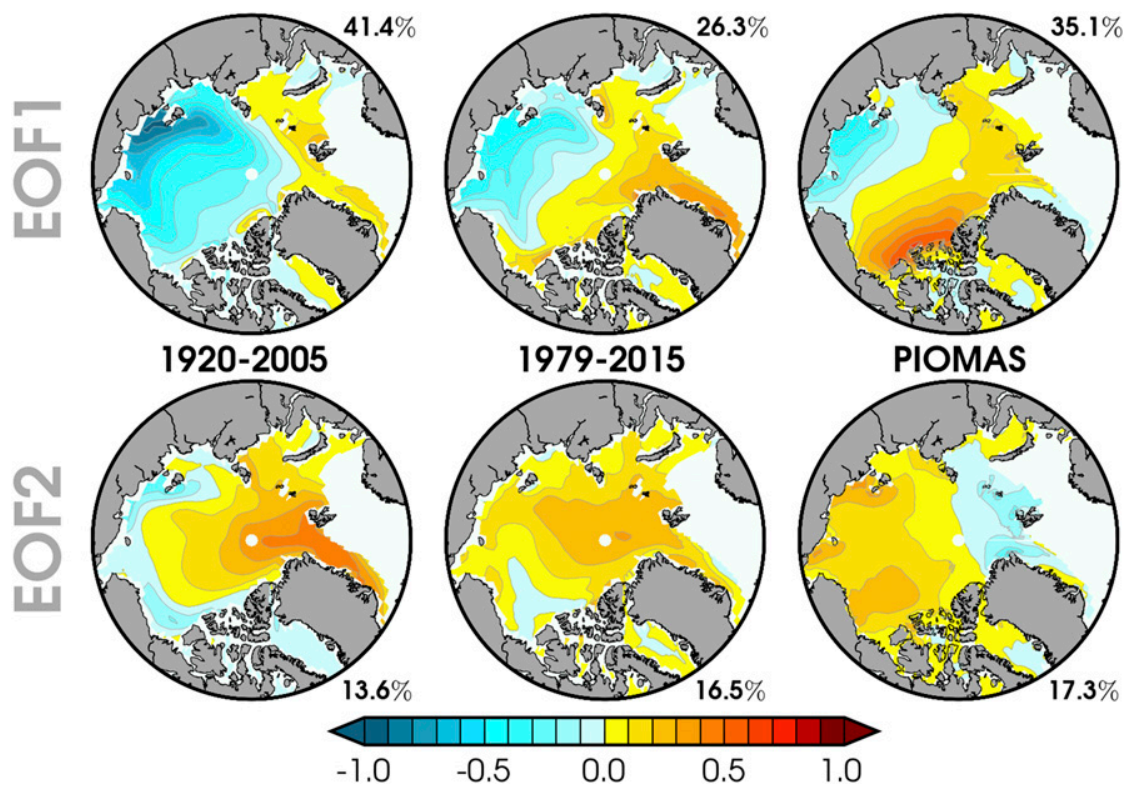

FIG. 7. Spatial patterns of the first two leading EOF modes (top: EOF1; bottom: EOF2) calculated from all monthly SIT fields in the (left) LENS historical simulations (1920-2005), (middle) LENS overlapping with PIOMAS (1979-2015), and (right) PIOMAS (1979-2015). Monthly SIT points are detrended (linearly) before computing the EOF analysis. The percentage of explained variance is given in the upper-/lower-right-hand corner for each of the EOF maps.

atmospheric circulation in the Northern Hemisphere extratropics, including the Arctic, and where a positive polarity drives sea ice away from the coast of Siberia toward the Fram Strait and leads to an increase in Arctic sea ice divergence (Rigor et al. 2002). The second leading mode in LENS (EOF2; representing 14\% of the variance) again has two opposite-sign centers of action: East Siberian Sea and Greenland Sea (Fram Strait). Thus, both EOFs show a dipole in sea ice thickness between the eastern and western Arctic, which underscores the importance of this pattern.

For consistency with the PIOMAS temporal record, we compute EOFs from 1979 through 2015 in LENS, shown in Fig. 7 (middle column). The first leading mode (EOF1; representing $26 \%$ of the variance) reflects the dipole structure of two opposite-sign centers of action, in the East Siberian to Laptev Seas and near the Fram Strait. The second leading mode in LENS from 1979 to 2015 (EOF2; representing $17 \%$ of the variance) reflects a slightly more homogeneous structure stretching from over the central Arctic to near Svalbard. We also see a decrease in the percentage variance, explained by the EOF1 composite in the 1979 to 2015 LENS.

The first leading mode in PIOMAS (EOF1; representing $35 \%$ of the variance) shares some common features with the east-west Arctic anomaly pattern (Zhang et al. 2000). The east-west Arctic anomaly pattern is a sea ice mass dipole anomaly between the Beaufort Sea and the East Siberian and Laptev Seas region. This dipole is enhanced during strongly positive NAM periods and acts to increase Fram export and, hence, leaves significantly reduced thickness in the eastern Arctic (Zhang et al. 2000). We see again the opposite centers of action from near the East Siberian Sea region to the Atlantic sector. PIOMAS's second leading mode (EOF2; representing $17 \%$ of the variance) is more homogenous, similar to LENS (1979-2015) EOF2, but shows a larger maximum anomaly from the Beaufort Sea to the New Siberian Islands region.

We find that LENS captures similar patterns of spatial variability as PIOMAS, shown in Fig. 4. The largest differences reside in the Beaufort Sea and Canadian Arctic Archipelago regions where PIOMAS' both EOF1 and EOF2 patterns feature a maximum anomaly, which is not present in LENS. The PIOMAS EOF1 spatial pattern is similarly captured by the interannual variability in Fig. 4 but extends farther from the immediate coastlines in the East Siberian and Beaufort Seas. We show late summer (JAS) SIT variability in Fig. 8 characterized by the standard deviation of LENS detrended SIT fields. In comparison to PIOMAS in Fig. 4, we see greater variability in the East Siberian Sea and less so north of the Canadian Arctic Archipelago, but the overall spatial patterns remain similar. A decrease in LENS SIT variability is 


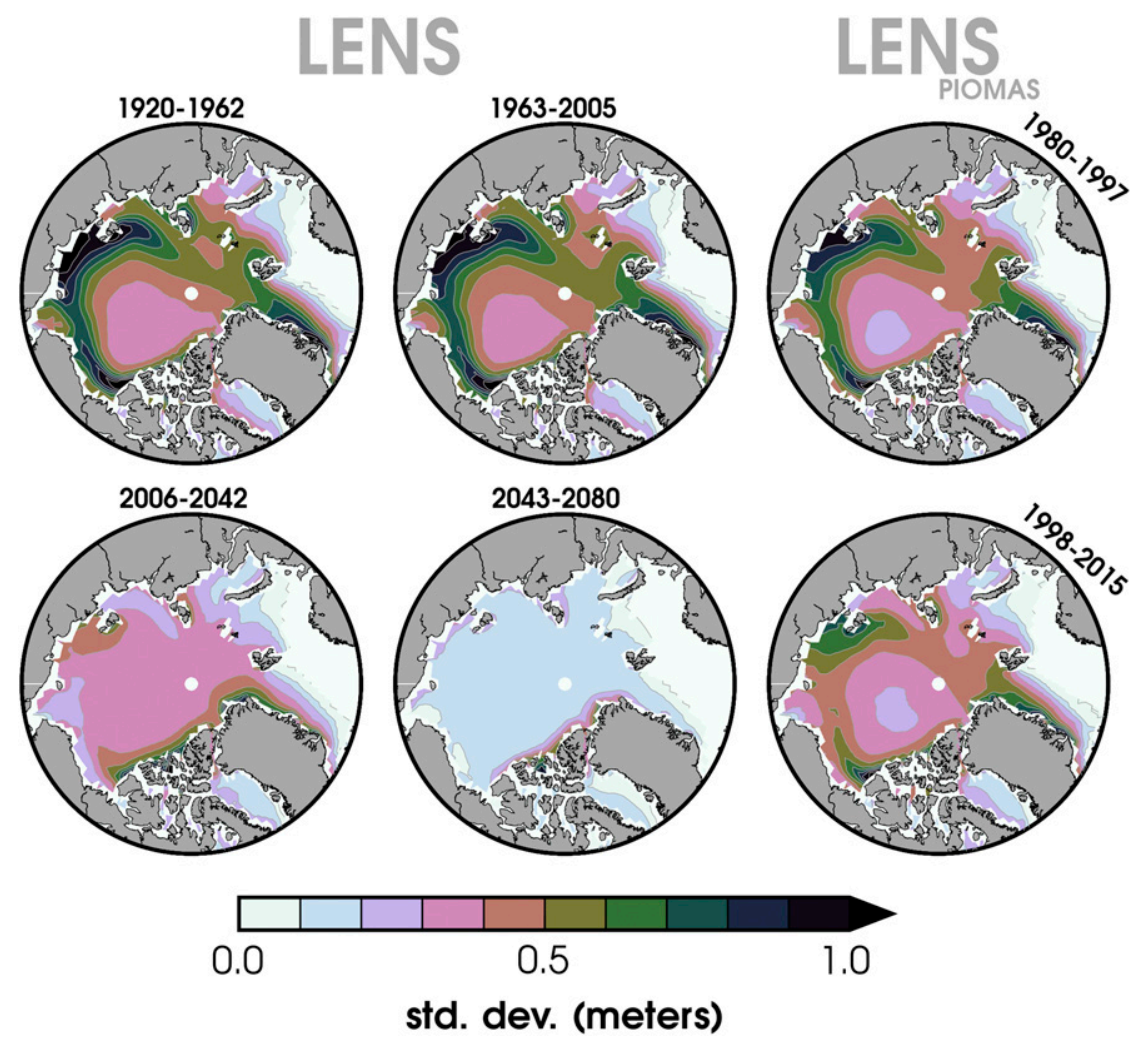

FIG. 8. Standard deviations (m) of LENS SIT averaged for July through September (JAS). The monthly SIT at each grid point is first linearly detrended. LENS composites are averaged over two equal periods per historical (1920-62 and 1963-2005) simulation and future (2006-42 and 2043-80) projections along with a closer comparison to PIOMAS over the period they share in common (1980-97 and 1998-2015). Contour intervals are $0.1 \mathrm{~m}$.

evident with time as sea ice becomes thinner over the Arctic Ocean. By the 2006-42 composite in Fig. 8, the greatest SIT variability is confined to the coastlines of Greenland and the Canadian Arctic Archipelago.

\section{c. LENS future projections of sea ice thickness (2006-80)}

Some characteristics of SIT in LENS projections were highlighted in Figs. 6e and 6f with substantially thinner ice across most of the Arctic Ocean, as well as the corresponding future SIT standard deviations (shown in Fig. 8) and SIT EOFs (shown in Fig. 7). During the mid2020 s, September ice is generally less than $1 \mathrm{~m}$, except for a small area north of Greenland and the Canadian Arctic Archipelago. By the end of the twenty-first century, September is less than 0.5 in all regions. In Fig. 9, we show the basinwide average SIT in LENS (all ensemble members in gray, ensemble mean in bold) over the historical period and projected to 2080 during the months of September (climatological minimum SIE) and March (climatological maximum SIE). Substantial spread is found in the historical simulations in September with an average of $1.1 \mathrm{~m}$ between the minimum and maximum SIT ensemble members (Fig. S3). There are also several outliers at more than $0.75 \mathrm{~m}$ from the mean. The ensemble spread decreases to approximately $0.5 \mathrm{~m}$ by 2080 between the minimum and maximum ensemble members. Moreover, spread decreases as SIT thins over the Arctic Ocean, which is partly due to the overall decrease in the mean SIT. As already discussed, areas of thin ice have reduced SIT variability. PIOMAS average SIT is outside the LENS envelope and approximately $0.5 \mathrm{~m}$ below the ensemble mean. Nevertheless, the rate of decline is similarly captured by the ensemble mean as in PIOMAS. Ensemble spread is smaller for March at an average of $0.8 \mathrm{~m}$ for the historical simulations and decreases to $0.4 \mathrm{~m}$ for the future projections (Fig. S3). There is minimal interannual variability in March after 2040. This timing is also consistent with the appearances of the first "ice free" SIE summers in LENS; nevertheless, a large spread in this timing still remains (Jahn et al. 2016).

A comparison of SIV (for the months September and March) between PIOMAS and LENS shows that PIOMAS is inherently lower than the LENS ensemble 


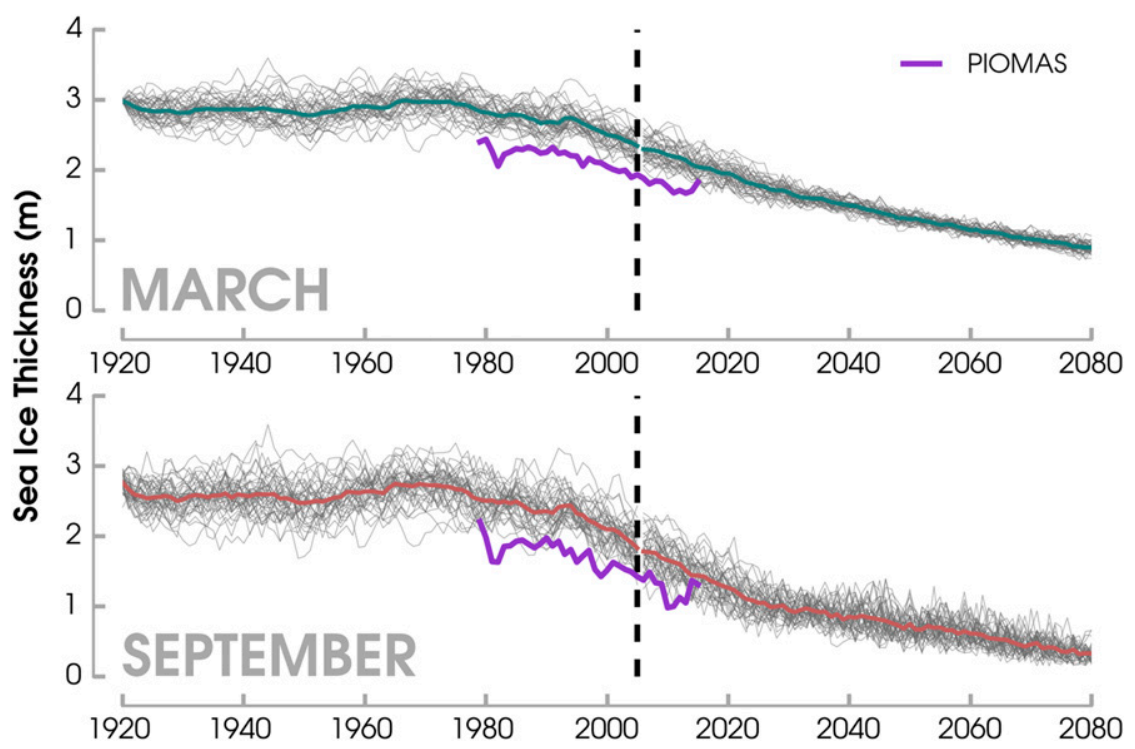

FIG. 9. Time series of (upper) March and (lower) September SIT (north of $65^{\circ} \mathrm{N}$ ) for LENS and PIOMAS (purple). Each LENS member indicated (gray) in addition to their ensemble mean (blue/red lines). The dashed vertical line separates the historical from the future LENS simulations.

mean in both months. LENS also has greater spread among ensemble members in September than March (not shown). Further, Fig. S4 shows that this internal variability contributes to a range between the 5 th and 95th percentiles of 2040-49 for the timing of the first mean-September SIV, dropping below $1000 \mathrm{~km}^{3}$ among ensemble members.

In Fig. 10, we show the September area-averaged SIT time series for each sea ice zone (Fig. S1) through 2080. All regions fall below $0.5 \mathrm{~m}$ in thickness during the future LENS period, but the timing of this event varies considerably. It occurs as early as the 2020s in the ensemble mean for the Barents-Kara, Laptev, and East Siberian Seas. Substantial thinning also occurs in the central Arctic basin. For the Greenland area, the mean-September SIT remains greater than $0.5 \mathrm{~m}$ for the better part of the period or until the 2060s. A corresponding time series plot for March (not shown) does not indicate any regions in the ensemble mean falling below $0.5-\mathrm{m}$ average thickness through 2080. If we examine the average timing of when the first September falls below $0.5 \mathrm{~m}$ SIT for each ensemble member, this occurs earlier than for the LENS ensemble mean and is shown in Fig. 11 for the different regions. The difference from the ensemble mean is especially pronounced in the regions of thinner ice, such as the Laptev and Barents-Kara Seas, where the 5th-95th percentile ensemble years range from 2002-22 and 1999-2021, respectively.

While twenty-first-century sea ice thins substantially in all seasons, a large sea ice cover continues to reform during the cold season. A region of perennially thick ice north of Greenland also remains. We note that there is a large spread between ensemble members of SIT greater than $1 \mathrm{~m}$ in all regions through at least 2020 , as seen in Fig. 10. The largest spread is found in the East Siberian and Laptev Seas. Consequently, the variance begins to decrease as average sea ice thins over the entire Arctic basin. This implies reduced uncertainty from future SIT internal variability.

Linear SIT trends over the same observational period (1979-2015) for LENS and PIOMAS (not shown) reveal close agreement in the rate of sea ice thinning. Comparing future LENS SIT linear trends (2006-80) with the previous PIOMAS record (1979-2015) shows little to no change in the rate of sea ice thinning in winter and spring and little spread among ensemble members, as seen in Fig. 12 (JFM, AMJ). The rate of thinning increases slightly in summer (JAS) and fall (OND), as seen by the increased spacing between the two vertical lines: the black line represents the LENS ensemble average, and the purple represents the PIOMAS record. The spread between ensemble members is largest in JAS and OND at approximately $0.25 \mathrm{~m} \mathrm{decade}^{-1}$. Evidence of regional variations in SIT have been well documented since the late 1950s (e.g., Rothrock et al. 1999; Rothrock and Zhang 2005; Rothrock et al. 2008) through submarine sea ice draft data and modeling experiments. In LENS, the rate of future thinning is similar in all six areas; however, sea ice loss accelerates near the climatologically thicker ice near the Canadian Arctic Archipelago 


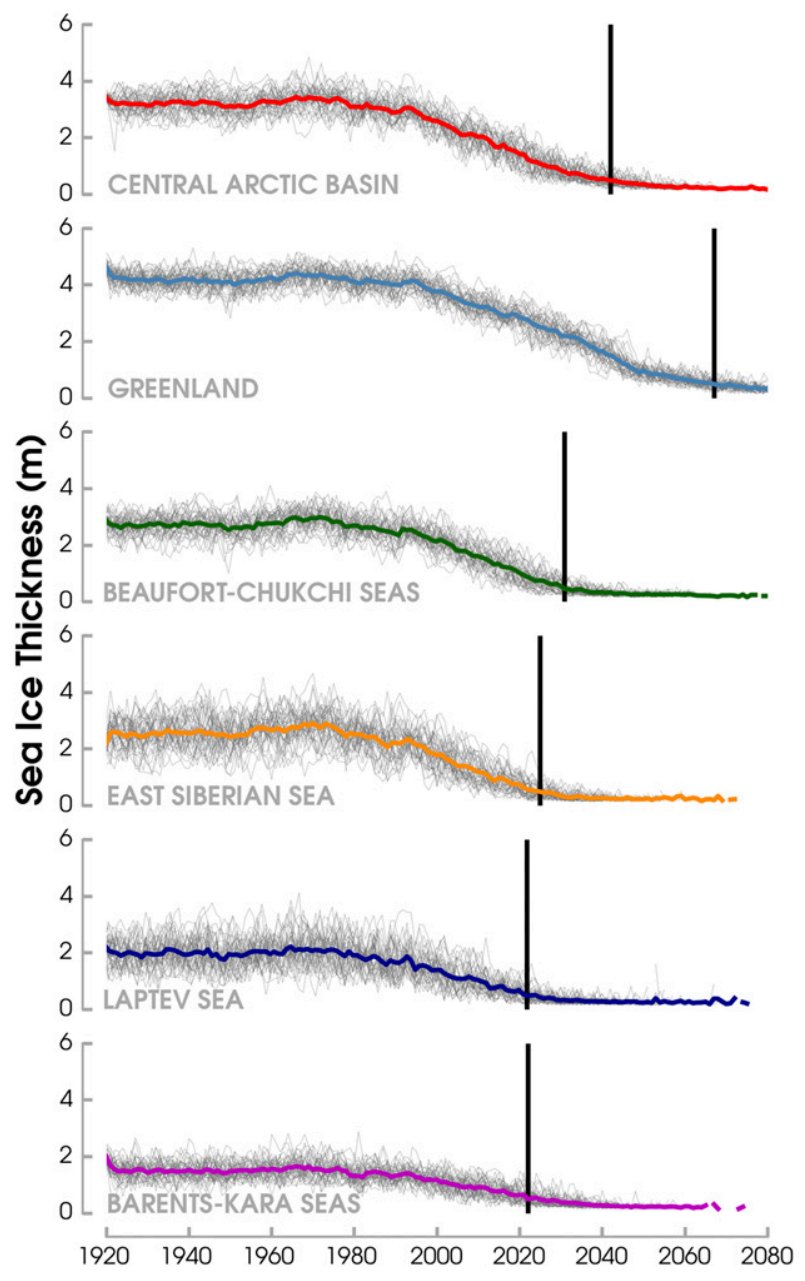

FIG. 10. Regional September SIT through the historical and future LENS time series (1920-2080) for all ensemble members (gray lines) and the ensemble means (bolded colored lines). The first instance of the average SIT at or below $0.5 \mathrm{~m}$ is shown by a vertical black line.

and Greenland (not shown). This is consistent with Bitz and Roe (2004) showing that areas of thicker ice have the greatest thinning.

\section{Summary and conclusions}

We use PIOMAS and LENS to assess the historical and future variability of Arctic SIT. To validate that we can use PIOMAS as a reanalysis dataset, we compare PIOMAS with SIT observations from submarine data and satellites. The key results of this study are summarized below.

1) PIOMAS realistically reproduces the spatial distribution of SIT when compared with satellite and submarine observations. We find long-term losses in Arctic SIT and SIV during all months of the year in

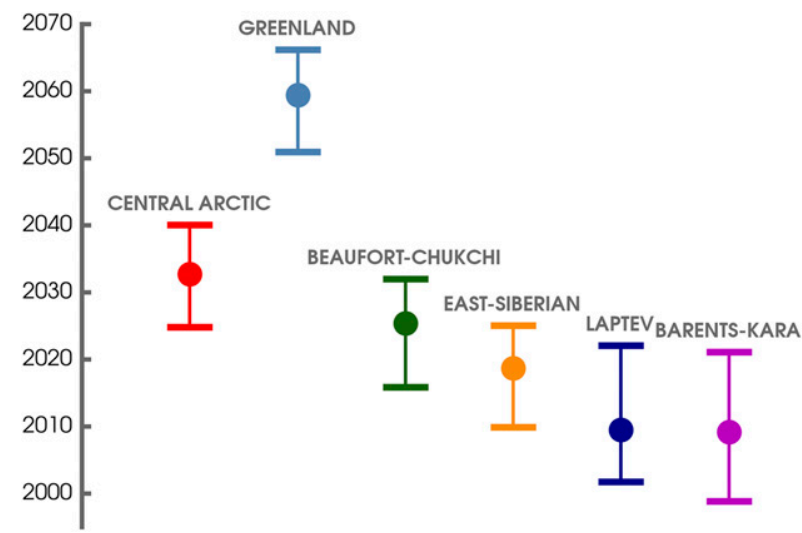

FIG. 11. Regional timing of the first September SIT to fall below $0.5 \mathrm{~m}$ averaged by each ensemble member's year (center point). The 5th-95th percentile years are visualized by the error bars.

the PIOMAS record (1979-2015), with the largest trends during the summer months (JAS). We find considerable spatial variability in seasonal PIOMAS SIT over the Beaufort, Chukchi, and East Siberian Seas and along coastal areas.

2) We show that LENS compares well with PIOMAS both in the regional distribution of mean SIT and in revealing similar patterns of spatial variability. The largest differences are in areas north of the Canadian Arctic Archipelago and coastal Greenland, where LENS simulates thicker sea ice. PIOMAS underestimates SIT in this region when compared with satellite and submarine observations. There is a documented negative bias in PIOMAS (Schweiger et al. 2011), and this likely contributes to the larger total SIV in LENS than PIOMAS. Compared with PIOMAS, the LENS annual mean also places significantly thicker sea ice near the New Siberian Islands in the East Siberian Sea.

The first EOF of the historical LENS (1920-2005) places a center of action over the East Siberian Sea with same-signed anomalies stretching over the entire Arctic. Opposite anomalies are found over the Atlantic side of the Arctic. The area of the East Siberian Sea has the greatest thinning in recent decades as obtained from PIOMAS. Using a similar model as PIOMAS, Rothrock and Zhang (2005) also find that the East Siberian Sea has the greatest loss in SIT through 1999. When considering only the time period 1979-2015 (the time of the PIOMAS record), the first mode of SIT variability in LENS shows a shrunken area around the East Siberian Sea center of action and the area of the opposite polarity now reaches deep into the Arctic, including north of Greenland. It is more similar to the PIOMAS first mode of variability, which has the primary center of 


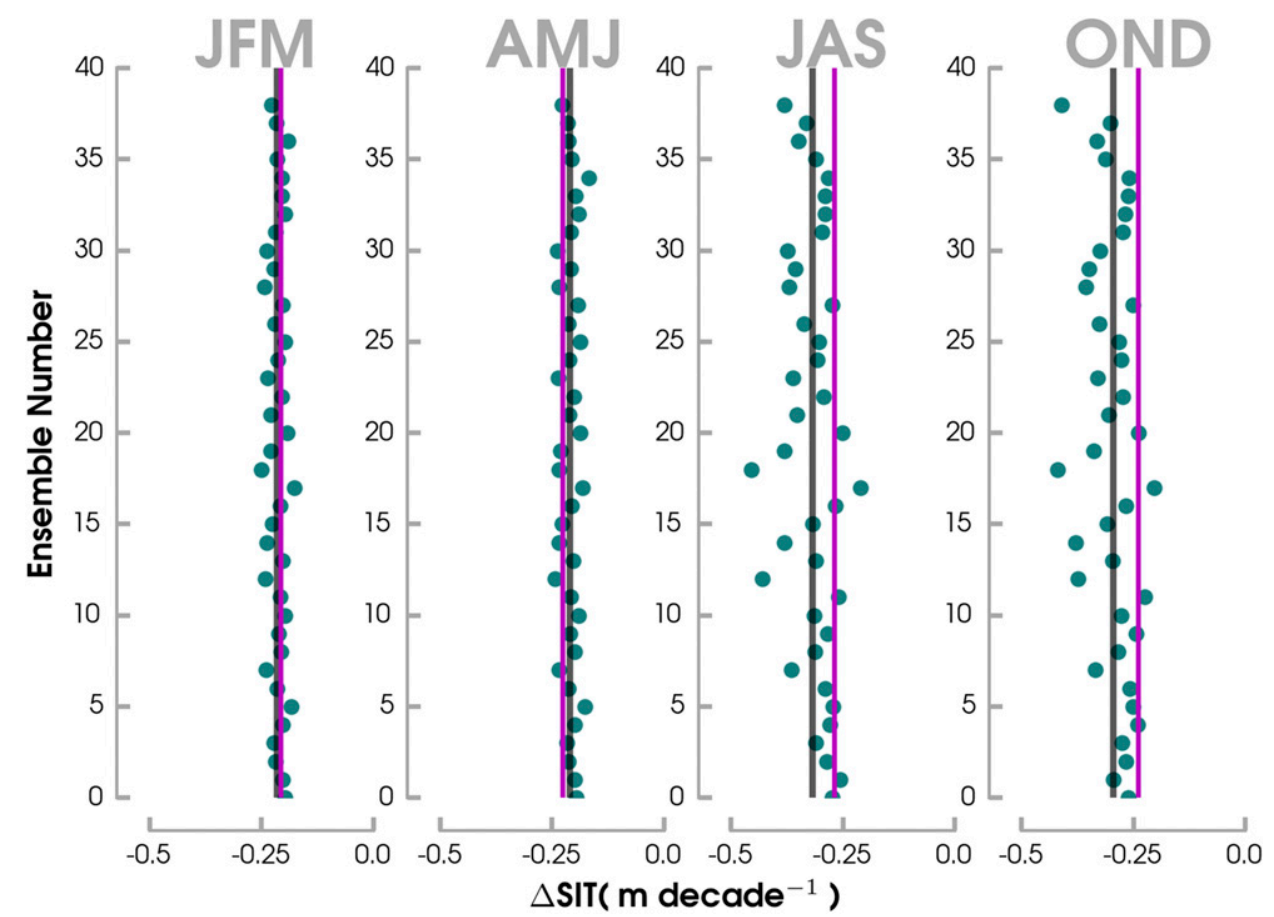

FIG. 12. Seasonal decadal trends in mean SIT averaged through the future LENS period (2006-80) from each ensemble member (blue points). Ensemble mean decadal trend (2006-80) shown by a vertical black line. PIOMAS SIT trends for the 1979-2015 period shown by a purple vertical line.

action north of Greenland with an area of opposite signed anomalies that is smaller in extent centered in the East Siberian Sea.

3) All LENS members indicate a long-term decrease in SIT across the Arctic Ocean through the end of the twenty-first century. Both September and March SIT in the entire LENS time series (1920-2080) show significant spread among individual ensemble members in the Beaufort, East Siberian, and Laptev Seas of approximately $2 \mathrm{~m}$ through 2020 . The large ensemble spread early on indicates that internal variability has an important role in determining regional SIT during all months. By the middle of the twentyfirst century and on, SIT becomes less sensitive to interannual changes in most regions, except for areas of thicker ice near Greenland. An area of perennially thick sea ice remains north of Greenland during all months of the year, but it significantly thins (especially in September) by the mid-twenty-first century. Average September SIT in all regions eventually falls below $0.5 \mathrm{~m}$ during the $21 \mathrm{st}$ century. However, the timing of this event varies by more than a decade among ensemble members. We also show that the timing of the first September SIT below $0.5 \mathrm{~m}$ occurs substantially earlier than the timing of that event for the ensemble mean in the outer marginal seas, but year-to-year variability remains. Recent summer sea ice conditions have already shown this to be the case, for instance, in the Barents-Kara Seas. Even in the area of climatologically thick sea ice north of Greenland, the first September with SIT less than $0.5 \mathrm{~m}$ is reached, on average, by $2059 \pm 7$ years. While future rates of declining SIT may temporarily slow or even pause as a result of this high internal variability and the resiliency of SIV (Tilling et al. 2015; Blanchard-Wrigglesworth and Bitz 2014), future simulations from LENS indicate a continued loss of thicker, multiyear sea ice and a reduction in interannual variability.

Our results are limited by any inherent bias in using the output of a coupled sea ice-ocean model (in this case, PIOMAS) as an SIT reanalysis dataset, as well as from any model bias due to CESM1.1. While PIOMAS has the capability to assimilate SIC and SST, additional improvements to other similar coupled sea ice-ocean models have been made by assimilating SIT observations (e.g., Xie et al. 2016). More satellite and in situ observations are especially needed in the East Siberian and Beaufort Seas, where there is substantial SIT variability.

A thinning sea ice cover will bring challenges to future sea ice prediction, as the response of SIE to atmospheric circulation patterns may change (Holland and Stroeve 
2011). Further idealized experiments using realistic long-term SIT data are also needed to assess the influences of a thinning sea ice cover on the local and large-scale atmospheric responses (Lang et al. 2017), such as that on Arctic amplification.

Acknowledgments. We acknowledge the CESM Large Ensemble Community Project and supercomputing resources provided by NCAR for making the CESM-LENS data available. Output from PIOMAS is available from the Polar Science Center at the University of Washington. Additional gridded observational sea ice thickness products are available from the NSIDC. We thank three anonymous reviewers for their suggestions and comments. This work was supported by NSF Grants AGS-1407360, AGS-1624038, and NRT-1633631.

\section{REFERENCES}

Andrews, T., J. M. Gregory, M. J. Webb, and K. E. Taylor, 2012: Forcing, feedbacks and climate sensitivity in CMIP5 coupled atmosphere-ocean climate models. Geophys. Res. Lett., 39, L09712, https://doi.org/10.1029/2012GL051607.

Barnhart, K. R., C. R. Miller, I. Overeem, and J. E. Kay, 2016: Mapping the future expansion of Arctic open water. Nat. Climate Change, 6, 280-285, https://doi.org/10.1038/nclimate2848.

Bitz, C. M., and G. H. Roe, 2004: A mechanism for the high rate of sea ice thinning in the Arctic Ocean. J. Climate, 17, 3623-3632, https:// doi.org/10.1175/1520-0442(2004)017<3623:AMFTHR>2.0.CO;2.

Blanchard-Wrigglesworth, E., and C. M. Bitz, 2014: Characteristics of Arctic sea-ice thickness variability in GCMs. J. Climate, 27, 8244-8258, https://doi.org/10.1175/JCLI-D-14-00345.1.

Brodzik, M. J., B. Billingsley, T. Haran, B. Raup, and M. H. Savoie, 2012: EASE-Grid 2.0: Incremental but significant improvements for Earth-gridded data sets. ISPRS Int. J. Geo-Inf., 1, 32-45, https://doi.org/10.3390/ijgi1010032.

Bushuk, M., R. Msadek, M. Winton, G. A. Vecchi, R. Gudgel, A. Rosati, and X. Yang, 2017: Summer enhancement of Arctic sea ice volume anomalies in the September-ice zone. J. Climate, 30, 2341-2362, https://doi.org/10.1175/JCLI-D-16-0470.1.

Dawson, A., 2016: EOFS: A library for EOF analysis of meteorological, oceanographic, and climate data. J. Open Res. Software, 4, e14, http://doi.org/10.5334/jors.122.

Holland, M. M., and J. Stroeve, 2011: Changing seasonal sea ice predictor relationships in a changing Arctic climate. Geophys. Res. Lett., 38, L18501, https://doi.org/10.1029/2011GL049303.

Hunke, E. C., and M. M. Holland, 2007: Global atmospheric forcing data for Arctic ice-ocean modeling. J. Geophys. Res., 112, C04S14, https://doi.org/10.1029/2006JC003640.

Jahn, A., J. E. Kay, M. M. Holland, and D. M. Hall, 2016: How predictable is the timing of a summer ice-free Arctic? Geophys. Res. Lett., 43, 9113-9120, https://doi.org/10.1002/ 2016GL070067.

Kay, J. E., M. M. Holland, and A. Jahn, 2011: Inter-annual to multidecadal Arctic sea ice extent trends in a warming world. Geophys. Res. Lett., 38, L15708, https://doi.org/10.1029/2011GL048008.

_ , and Coauthors, 2015: The Community Earth System Model (CESM) Large Ensemble Project: A community resource for studying climate change in the presence of internal climate variability. Bull. Amer. Meteor. Soc., 96, 1333-1349, https:// doi.org/10.1175/BAMS-D-13-00255.1.

Kwok, R., and G. F. Cunningham, 2008: ICESat over Arctic sea ice: Estimation of snow depth and ice thickness. J. Geophys. Res., 113, C08010, https://doi.org/10.1029/2008JC004753.

— from submarine and ICESat records: 1958-2008. Geophys. Res. Lett., 36, L15501, https://doi.org/10.1029/2009GL039035.

Lang, A., S. Yang, and E. Kaas, 2017: Sea ice thickness and recent Arctic warming. Geophys. Res. Lett., 44, 409-418, https://doi.org/ 10.1002/2016GL071274.

Laxon, S. W., and Coauthors, 2013: CryoSat-2 estimates of Arctic sea ice thickness and volume. Geophys. Res. Lett., 40, 732-737, https://doi.org/10.1002/grl.50193.

Lindsay, R., 2010: New unified sea ice thickness climate data record. Eos, Trans. Amer. Geophys. Union, 91, 405-406, https:// doi.org/10.1029/2010EO440001.

— , and J. Zhang, 2006: Arctic Ocean ice thickness: Modes of variability and the best locations from which to monitor them. J. Phys. Oceanogr., 36, 496-506, https://doi.org/10.1175/ JPO2861.1.

—_, and A. Schweiger, 2015: Arctic sea ice thickness loss determined using subsurface, aircraft, and satellite observations. Cryosphere, 9, 269-283, https://doi.org/10.5194/ tc-9-269-2015.

_ M. Wensnahan, A. Schweiger, and J. Zhang, 2014: Evaluation of seven different atmospheric reanalysis products in the Arctic. J. Climate, 27, 2588-2606, https://doi.org/10.1175/ JCLI-D-13-00014.1.

Manda, A., N. Hirose, and T. Yanagi, 2005: Feasible method for the assimilation of satellite-derived SST with an ocean circulation model. J. Atmos. Oceanic Technol., 22, 746-756, https://doi.org/ 10.1175/JTECH1744.1.

Melia, N., K. Haines, and E. Hawkins, 2015: Improved Arctic sea ice thickness projections using bias-corrected CMIP5 simulations. Cryosphere, 9, 2237-2251, https://doi.org/10.5194/ tc-9-2237-2015.

Parkinson, C. L., and W. M. Washington, 1979: A large-scale numerical model of sea ice. J. Geophys. Res., 84, 311-337, https:// doi.org/10.1029/JC084iC01p00311.

— new information on the contrasting Arctic and Antarctic seaice trends since the late 1970s. Remote Sens. Environ., 183, 198-204, https://doi.org/10.1016/j.rse.2016.05.020.

Peings, Y., and G. Magnusdottir, 2014: Response of the wintertime Northern Hemisphere atmospheric circulation to current and projected Arctic sea ice decline: A numerical study with CAM5. J. Climate, 27, 244-264, https://doi.org/10.1175/ JCLI-D-13-00272.1.

Rigor, I. G., J. M. Wallace, and R. L. Colony, 2002: Response of sea ice to the Arctic Oscillation. J. Climate, 15, 2648-2663, https:// doi.org/10.1175/1520-0442(2002)015<2648:ROSITT>2.0.CO;2.

Rothrock, D. A., and J. Zhang, 2005: Arctic Ocean sea ice volume: What explains its recent depletion? J. Geophys. Res., 110, C01002, https://doi.org/10.1029/2004JC002282.

_, Y. Yu, and G. A. Maykut, 1999: Thinning of the Arctic sea-ice cover. Geophys. Res. Lett., 26, 3469-3472, https://doi.org/ 10.1029/1999GL010863.

- D. B. Percival, and M. Wensnahan, 2008: The decline in Arctic sea-ice thickness: Separating the spatial, annual, and interannual variability in a quarter century of submarine data. J. Geophys. Res., 113, C05003, https://doi.org/10.1029/ 2007JC004252. 
Schweiger, A., R. Lindsay, J. Zhang, M. Steele, H. Stern, and R. Kwok, 2011: Uncertainty in modeled Arctic sea ice volume. J. Geophys. Res., 116, C00D06, https://doi.org/10.1029/2011JC007084.

Serreze, M. C., and J. Stroeve, 2015: Arctic sea ice trends, variability and implications for seasonal ice forecasting. Philos. Trans. Roy. Soc. London, 373A, 20140159, https://doi.org/10.1098/rsta.2014.0159.

, — - A. P. Barrett, and L. N. Boisvert, 2016: Summer atmospheric circulation anomalies over the Arctic Ocean and their influences on September sea ice extent: A cautionary tale. J. Geophys. Res. Atmos., 121, 11463-11485, https://doi.org/ 10.1002/2016JD025161.

Smith, R. D., J. K. Dukowicz, and R. C. Malone, 1992: Parallel ocean general circulation modeling. Physica D, 60, 38-61, https://doi.org/10.1016/0167-2789(92)90225-C.

Stroeve, J., A. Barrett, M. Serreze, and A. Schweiger, 2014: Using records from submarine, aircraft and satellites to evaluate climate model simulations of Arctic sea ice thickness. Cryosphere, 8, 1839-1854, https://doi.org/10.5194/tc-8-1839-2014.

Swart, N. C., 2017: Climate variability: Natural causes of Arctic seaice loss. Nat. Climate Change, 7, 239-241, https://doi.org/ 10.1038/nclimate3254.

_ J. C. Fyfe, E. Hawkins, J. E. Kay, and A. Jahn, 2015: Influence of internal variability on Arctic sea-ice trends. Nat. Climate Change, 5, 86-89, https://doi.org/10.1038/nclimate2483.

Tilling, R. L., A. Ridout, A. Shepherd, and D. J. Wingham, 2015: Increased Arctic sea ice volume after anomalously low melting in 2013. Nat. Geosci., 8, 643-646, https://doi.org/10.1038/ngeo2489.
Wang, X., J. Key, R. Kwok, and J. Zhang, 2016: Comparison of Arctic sea ice thickness from satellites, aircraft, and PIOMAS data. Remote Sens., 8, 713, https://doi.org/10.3390/ rs8090713.

Warren, S. G., I. G. Rigor, N. Untersteiner, V. F. Radionov, N. N. Bryazgin, Y. I. Aleksandrov, and R. Colony, 1999: Snow depth on Arctic sea ice. J. Climate, 12, 1814-1829, https://doi.org/ 10.1175/1520-0442(1999)012<1814:SDOASI >2.0.CO;2.

Xie, J., F. Counillon, L. Bertino, X. Tian-Kunze, and L. Kaleschke, 2016: Benefits of assimilating thin sea ice thickness from SMOS into the TOPAZ system. Cryosphere, 10, 2745-2761, https://doi.org/10.5194/tc-10-2745-2016.

Zhang, J., and D. A. Rothrock, 2003: Modeling global sea ice with a thickness and enthalpy distribution model in generalized curvilinear coordinates. Mon. Wea. Rev., 131, 845-861, https://doi.org/ 10.1175/1520-0493(2003)131<0845:MGSIWA > 2.0.CO;2.

- D. Rothrock, and M. Steele, 2000: Recent changes in Arctic sea ice: The interplay between ice dynamics and thermodynamics. J. Climate, 13, 3099-3114, https://doi.org/10.1175/ 1520-0442(2000)013<3099:RCIASI >2.0.CO;2.

Zwally, H., and Coauthors, 2002: ICESat's laser measurements of polar ice, atmosphere, ocean, and land. J. Geodyn., 34, 405-445, https://doi.org/10.1016/S0264-3707(02)00042-X.

Zygmuntowska, M., P. Rampal, N. Ivanova, and L. H. Smedsrud, 2014: Uncertainties in Arctic sea ice thickness and volume: New estimates and implications for trends. Cryosphere, 8 , 705-720, https://doi.org/10.5194/tc-8-705-2014. 